\title{
PENGARUH MASSASE MENGGUNAKAN OLIVE OIL TERHADAP NYERI DISMENORE PADA MAHASISWI JURUSAN KEPERAWATAN STIKES TRI MANDIRI SAKTI BENGKULU
}

\author{
Pawiliyah \\ Program Studi ILmu Keperawatan STIKES Tri Mandiri Sakti Bengkulu \\ Email: pawiliyah@yahoo
}

\begin{abstract}
ABSTRAK
Masalah kesehatan reproduksi seperti dismenore adalah masalah yang berhubungan dengan menstruasi. Berdasarkan hasil survei pendahuluan dari peneliti pada 10 mahasiswa Keperawatan STIKES Tri Mandiri Sakti Bengkulu yang mengalami dismenore yang didapat semuanya mengatakan mereka tidak mengerti bagaimana cara mengatasi rasa sakit dismenorea dan hanya mengonsumsi obat-obatan yang dipercepat untuk mengurangi rasa sakit. Berdasarkan uraian di atas, peneliti tertarik untuk melakukan penelitian tentang efek penggunaan minyak zaitun pada nyeri dismenore. Tujuan dari penelitian ini adalah untuk menentukan pijat menggunakan minyak zaitun untuk nyeri dismenore pada mahasiswa keperawatan. Penelitian ini menggunakan desain Pra-Eksperimen dengan Desain One Group Pretest Postest. Populasi dalam penelitian ini adalah seluruh mahasiswa Jurusan Keperawatan STIKES Tri Mandiri Sakti Bengkulu dengan jumlah 30 orang. Teknik pengambilan sampel dalam penelitian ini menggunakan teknik total sampling. Pengumpulan data dalam penelitian ini menggunakan data primer yang diperoleh melalui studi langsung pada Mahasiswa Jurusan Keperawatan STIKES Tri Mandiri Sakti Bengkulu. Analisis data menggunakan univariat dan bivariat. Hasil penelitian ini menunjukkan uji Wilcoxon Match Pair Test diperoleh nilai $Z=2,781$ dengan $p=0,005<0,05$ berarti signifikan, sehingga Ho ditolak dan Ha diterima. Ada efek pengaruh massase menggunakan olive oil terhadap nyeri Dismenore pada Mahasiswa Jurusan Keperawatan Tri Mandiri Sakti Bengkulu. Pentingnya meningkatkan sumber informasi bagi siswa yang mengalami dismenore untuk dapat melakukan pijatan menggunakan olive oil ketika mengalami dismenore untuk mengurangi dan mengelola nyeri dismenore sebagai langkah utama untuk mengatasi nyeri dismenore dan mengurangi penggunaan obat-obatan menstruasi.
\end{abstract}

Kata kunci : Massase, olive oil, nyeri, disminore.

\section{Effect of massage using olive oil to dysmenorrhea pain on Students of Nursing}

\begin{abstract}
Reproductive health problems such as dysmenorrhea is problem associated with menstruation. Based on the results of the preliminary survey of researchers on 10 Nursing students of STIKES Tri Mandiri Sakti Bengkulu who experienced dysmenorrhea obtained all said they did not understand how to deal with the pain of dysmenorrhoea and only consumed expediting drugs to reduce feelings pain. Based on the description above, researchers are interested in conducting research on the effect of massase using olive oil on dysmenorrhea pain. The aims of this study was to determine massage using olive oil to dysmenorrhea pain on student of nursing. This study used Pre-Experiment
\end{abstract}


design with The One Group Pretest Postest Design. Population in this study were all students of Nursing Program Tri Mandiri Sakti Bengkulu Institute of Health Sciences with the amount of 30 people. Sampling technique in this study used total sampling techniques Data collection in this study used primary data obtained through direct study on Students of Nursing Program Tri Mandiri Sakti Bengkulu Institute of Health Sciences. Data analysis used univariate and bivariate. The results of this study showed Wilcoxon Match Pair Test test obtained a value of $Z=2.781$ with $p=0.005<0.05$ means significant, so that Ho is rejected and Ha is accepted. There is effect Effect of massage using olive oil to Dysmenorrhea pain on Students of Nursing Program Tri Mandiri Sakti Bengkulu Institute of Health Sciences. The importance of increase the source of information for students who experience dysmenorrhea to be able to do massage using olive oil when experiencing dysmenorrhea to reduce and manage dysmenorrhea pain as the main step to overcome dysmenorrhea pain and reduce utilization of menstrual drugs.

\section{Keywords: Massage, Olive oil, Pain, Dysmenorrhe}

\section{Pendahuluan}

Masalah kesehatan reproduksi seperti dismenore yang merupakan masalah yang berhubungan dengan menstruasi. Rasa sakit dimulai dari beberapa jam sebelum atau bersamaan dengan timbulnya menstruasi dan berlangsung selama 48 hingga 72 jam. Nyeri juga dapat disertai dengan kram perut di bagian bawah yang dihasilkan dari kontraksi di dalam rahim, yang merupakan bagian normal dari proses menstruasi, dan biasanya pertama kali dirasakan ketika mulai pendarahan dan berlanjut selama 32-48 jam (Reeder, 2011).

\section{Studi di Amerika} menunjukkan prevalensi tertinggi nyeri haid pada wanita remaja, yaitu antara $20-90 \%$. Sekitar $15 \%$ dari remaja melaporkan nyeri haid ke tingkat yang parah dan tidak menyebabkan kehadiran di sekolah. Sementara penelitian di Swedia menemukan prevalensi dismenorea terjadi pada 90\% wanita berusia 19 tahun, 67\% wanita 24 tahun yang mengalami dismenore melaporkan nyeri yang mengganggu fungsi sehari-hari. Upaya yang dilakukan oleh para remaja ini untuk mengatasi rasa sakit dengan meminum obat-obatan yang dijual bebas dan beberapa dari mereka berkonsultasi dengan dokter. (Perancis, 2014)

Insiden dismenore di Indonesia adalah $(64,25 \%)$ yang terdiri dari $(54,89 \%)$ dismenore primer dan (9,36\%) dismenore sekunder (Proverawati, 2012). Penggunaan metode farmakologis adalah pengobatan pertama yang biasanya dilakukan ketika nyeri haid adalah untuk memberikan penghilang rasa sakit dan $80 \%$ pasien mengalami penurunan nyeri haid setelah menggunakan prostaglandin inhibitor (Speroff dan Fritzz, 2013).

$$
\text { Perawatan menggunakan }
$$

metode non-farmakologis, salah satunya adalah dapat menggunakan metode pijatan untuk mengurangi rasa sakit saat menstruasi, salah satunya 
adalah dengan melakukan effleurage pijat. Pijat effleurage adalah tindakan memijat menggunakan kedua telapak tangan di perut dan secara bersamaan bergerak dalam lingkaran menuju pusat simfisis (Agustina, T. W, 2016).

Penggunaan metode massase dengan menggunakan aromaterapi dapat digunakan sebagai media untuk rileks sakit perut sehingga memiliki efek menenangkan, meningkatkan keseimbangan, pikiran positif, kejernihan pikiran, ketenangan pikiran. Juga dapat mengurangi depresi, kecemasan, stres. (Agustina, T. W, 2016).

Nuzul Eka Yoganita et al (2019), yang berjudul "Manfaat pijat tengkuk dengan minyak zaitun untuk mengurangi sakit kepala penderita hipertensi dengan hasilnya ada efek tengkuk dengan minyak zaitun dalam mengurangi sakit kepala penderita hipertensi dengan nilai p 0,001 .

Berdasarkan hasil survei pendahuluan dari peneliti pada 10 mahasiswa Keperawatan STIKES Tri Mandiri Sakti Bengkulu yang mengalami dismenore diperoleh semua mengatakan mereka tidak mengerti bagaimana cara mengatasi rasa sakit dismenorea dan hanya mengonsumsi obat-obatan yang dipercepat untuk mengurangi rasa sakit. Berdasarkan uraian di atas, peneliti tertarik untuk melakukan penelitian tentang efek penggunaan massase dengan menggunakan olive oil pada nyeri dismenore

\section{Metode Penelitian}

Desain yang digunakan dalam penelitian ini adalah Pra-Eksperimental menggunakan The One Group Pretest Postest Design. Lokasi penelitian ini dilakukan di Tri Mandiri Sakti, Bengkulu. Subjek Penelitian populasi dalam penelitian ini adalah seluruh mahasiswa Program studi Keperawatan STIKES Tri Mandiri Sakti Bengkulu dengan jumlah 30 orang yang mengalami disminore. Teknik pengambilan sampel dalam penelitian ini menggunakan teknik total sampling. Pengumpulan data dalam penelitian ini menggunakan data primer yang diperoleh melalui studi langsung pada Mahasiswa Program Studi Keperawatan STIKES Tri Mandiri Sakti Bengkulu.

Instrumen dalam penelitian ini menggunakan lembar observasi dan instrumen nyeri menurut intensitas nyeri Smeltzer \& Bare (2013) dapat ditentukan dengan meminta pasien melalui skala nyeri.

Analisis data dilakukan dengan analisis univariat dan bivariat. Data normalitas menggunakan SaphiroWilk karena sampel $<50$ orang. Uji statistik menggunakan paired sample T-test.

\section{Hasil penelitian dan pembahasan \\ 1. Analisis Univariat}

Analisis ini dilakukan untuk mendapatkan gambaran tentang gambaran masing-masing variabel yang diteliti, baik variabel 
independen maupun variabel dependen.

a. Gambaran nyeri dismenore sebelum diberikan massase menggunakan olive oil

Tabel 1

Gambaran nyeri dismenore sebelum diberikan massase menggunakan olive oil pada mahasiswi Jurusan Keperawatan STIKES Tri Mandiri Sakti Bengkulu

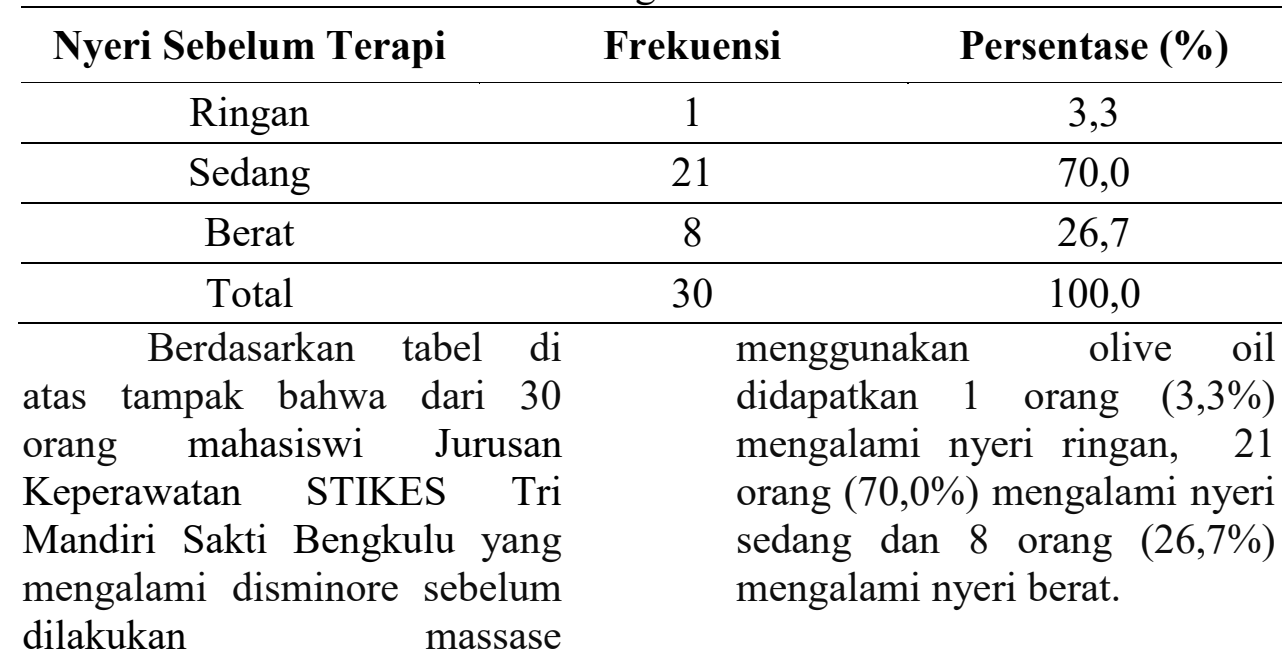

b. Gambaran nyeri dismenore setelah diberikan massase menggunakan olive oil

Tabel 2

Gambaran nyeri dismenore setelah diberikan massase menggunakan olive oil pada mahasiswi Jurusan Keperawatan STIKES Tri Mandiri Sakti

Bengkulu

\begin{tabular}{|c|c|}
\hline Nyeri Setelah Terapi & Persentase (\%) \\
\hline Ringan & 13,3 \\
\hline Sedang & 83,3 \\
\hline Berat & 3,3 \\
\hline Total & 100.0 \\
\hline $\begin{array}{lcrr} & \text { Berdasarkan tabel } & \text { di } \\
\text { atas tampak bahwa } & \text { dari } & 30 \\
\text { orang } & \text { mahasiswi } & \text { Jurusan }\end{array}$ & $\begin{array}{l}\text { sedang dan } 1 \text { orang }(3,3 \%) \\
\text { mengalami nyeri berat.. } \\
\text { 2. Uji Normalitas }\end{array}$ \\
\hline $\begin{array}{lrr}\text { Keperawatan } & \text { STIKES } & \text { Tri } \\
\text { Mandiri Sakti Bengkulu yang } \\
\text { mengalami disminore setelah } \\
\text { dilakukan } 4 \\
\text { menggunakan olive } r \text { oil } \\
\text { didapatkan 4 orang }(13,3 \%) \\
\text { mengalami nyeri ringan, } 25\end{array}$ & $\begin{array}{l}\text { Uji kenormalan data dalam } \\
\text { penelitian ini menggunakan uji } \\
\text { Shapiro-Wilk (karena sampel } \\
\text { kurang dari 50) untuk masing- } \\
\text { masing data variabel. Kriteria data } \\
\text { berdistribusi normal jika nilai } \\
\text { signifikansi lebih besar dari taraf }\end{array}$ \\
\hline
\end{tabular}


signifikansi $0,05(p>\alpha)$ dari masing masing variabel.

Tabel 3

Uji normalitas data nyeri dismenore responden sebelum dan setelah dilakukan massase menggunakan olive oil pada mahasiswi Jurusan Keperawatan STIKES Tri Mandiri Sakti Bengkulu

\begin{tabular}{l|l|l}
\hline Variabel & $\mathrm{P}$ & Keterangan \\
\hline Nyeri sebelum terapi & 0,006 & Datatidak berdistribusi normal \\
\hline Nyeri setelah terapi & 0,007 & Datatidak berdistribusi normal \\
\hline
\end{tabular}

Berdasarkan hasil uji normalitas, pada data tingkat nyeri sebelum terapi massase menggunakan olive oil didapat nilai $p=0,006<0,05$, maka dapat disimpulkan bahwa data tingkat nyeri sebelum dilakukan massase menggunakan olive oil pada mahasiswi Jurusan Keperawatan STIKES Tri Mandiri Sakti Bengkulu tidak berdistribusi normal.

Pada data tingkat nyeri setelah terapi massase menggunkan olive oil didapat nilai $p=0,007<$ 0,05 , maka dapat disimpulkan bahwa data tingkat nyeri setelah dilakukan massase menggunakan olive oil pada mahasiswi Jurusan Keperawatan Tingkat I dan II STIKES Tri Mandiri Sakti Bengkul tidak berdistribusi normal.

\section{Analisis Bivariat}

Analisis Bivariat dilakukan untuk mengetahui pengaruh

massase menggunakan olive oil terhadap nyeri dismenore pada mahasiswi mahasiswi Jurusan Keperawatan STIKES Tri Mandiri Sakti Bengkulu dengan melakukan uji Wilcoxon Match Pair Test karena data tidak berdistribusi normal. dengan hasil sebagai berikut:

Tabel 4.

Pengaruh massase menggunakan olive oil terhadap nyeri dismenore pada mahasiswi Jurusan Keperawatan STIKES Tri Mandiri Sakti Bengkulu

\begin{tabular}{cccc}
\hline & N & Z & P \\
\hline Negative Ranks & 14 & & \\
\cline { 1 - 1 } Positive Ranks & 2 & $-2,781$ & 0,005 \\
\hline Ties & 14 & & \\
\hline Total & 30 & & \\
\hline
\end{tabular}


Berdasarkan hasil penelitian didapatkan dari 30 orang mahasiswi Jurusan Keperawatan STIKES Tri Mandiri Sakti Bengkulu setelah dilakukan massase menggunakan olive oil terdapat 14 orang mengalami penurunan nyeri, 2 orang mengalami peningkatan nyeri dan 14 orang tidak mengalami perubahan nyeri.

Hasil uji Wilcoxon Match Pair Test didapat nilai $Z=2,781$ dengan $p=0,005<0,05$ berarti signifikan, sehingga Ho ditolak dan Ha diterima. Disimpulkan ada pengaruh massase menggunakan olive oil terhadap nyeri dismenore pada mahasiswi Jurusan Keperawatan STIKES Tri Mandiri Sakti Bengkulu

\section{Pembahasan}

Berdasarkan hasil penelitian

tampak bahwa dari 30 mahasiswi Keperawatan STIKES Tri Mandiri Sakti Bengkulu yang mengalami disminore sebelum dipijat menggunakan olive oil ditemukan 1 orang $(3,3 \%)$ mengalami sakit ringan, 21 orang $(70,0 \%) \quad$ ) mengalami sakit sedang dan 8 orang $(26,7 \%)$ mengalami sakit parah. Ini menunjukkan bahwa rasa sakit itu subyektif karena respons setiap orang terhadap rasa sakit dapat berbeda tergantung pada orang yang merasakannya meskipun dengan keadaan yang relatif sama.

Hasil penelitian ini sesuai dengan teori menurut Hidayat (2011) yang menyatakan bahwa nyeri adalah suatu kondisi dalam bentuk perasaan tidak menyenangkan yang sangat subyektif karena perasaan nyeri berbeda pada setiap orang dalam hal skala atau level, dan hanya orang itu dapat menjelaskan atau mengevaluasi rasa sakit yang dialaminya Menurut Harel (2011) selama menstruasi kombinasi peningkatan kadar prostagladin dapat terjadi dengan peningkatan sensitivitas miometrium, menyebabkan tekanan intra-uterus hingga $400 \mathrm{mmHg}$ dan dapat menyebabkan kontraksi miometrium yang parah. Oleh karena itu disimpulkan bahwa prostaglandin yang diproduksi oleh rahim dapat berperan dalam menyebabkan hiperaktivitas miometrium. prostagladin menyebabkan kontraksi miometrium sehingga akan mengurangi aliran darah.

Menurut peneliti bahwa setiap rasa sakit yang dirasakan oleh setiap individu sangat berbeda, menurut persepsi individu dalam merasakan rasa sakit yang mereka alami, berdasarkan faktor-faktor yang mempengaruhi intensitas rasa sakit itu sendiri, dalam teori Smeltzer dan Bare (2010) menyatakan bahwa dalam berbagai penelitian menemukan faktor-faktor yang dapat memengaruhi rasa sakit berasal dari usia, perhatian, kecemasan, makna nyeri, pengalaman masa lalu dan pekerjaan, pengetahuan, keluarga dan dukungan sosial. Jadi para peneliti menyimpulkan bahwa rasa sakit pada setiap orang akan berbeda walaupun pencetusnya sama, karena ada banyak hal yang dapat mempengaruhi persepsi setiap orang.

Berdasarkan hasil penelitian ditemukan bahwa dari 30 siswa STIKES Tri Mandiri Sakti Bengkulu yang mengalami disminore sebelum dipijat menggunakan olive oil ditemukan 4 orang $(13,3 \%)$ mengalami sakit ringan, 25 orang $(83,3) \%)$ mengalami sakit sedang dan 1 orang $(3,3 \%)$ mengalami sakit parah. Kondisi di atas menunjukkan bahwa telah terjadi penurunan skala rasa sakit rata-rata pada mahasiswa Jurusan Keperawatan STIKES Tri Mandiri Sakti Bengkulu yang mengalami disminores setelah pijat menggunakan olive oil. 
Hasil penelitian ini sesuai dengan teori Smeltzer \& Bare, (2010) yang menyatakan bahwa terapi massase dapat mengurangi intensitas nyeri melalui suatu mekanisme, sehingga dapat merelaksasikan otot rangka yang mengalami kejang karena disebabkan oleh peningkatan pada prostaglandin sehingga vasodilatasi terjadi di pembuluh darah dan kemudian meningkatkan aliran darah ke daerah yang mengalami kejang dan iskemia. Selain itu, teknik terapi massase dapat dipercaya untuk merangsang tubuh untuk melepaskan opoiods endogen, endorfin dan ensefalin. Teknik pemijatan bisa menghilangkan rasa sakit, karena aktivitas dalam serat besar dirangsang oleh tindakan ini, sehingga gerbang untuk aktivitas serat berdiameter kecil (nyeri) bisa ditutup.

Menurut peneliti, intensitas rasa sakit setelah intervensi mengalami penurunan karena intervensi teknik terapi massase menggunakan minyak zaitun mampu mengendalikan atau menghilangkan rasa sakit pada siswa yang mengalami dismenore. Hal ini disebabkan oleh pemberian teknik massase menggunakan minyak zaitun itu sendiri, jika massase dilakukan dengan benar maka akan menyebabkan penurunan rasa sakit yang dirasakan sangat berkurang / optimal dan responden dapat merasa lebih nyaman dari sebelumnya, sebaliknya jika aroma massase terapi minyak zaitun dilakukan secara tidak benar, maka rasa sakitnya sedikit berkurang tetapi masih terasa sakit dan pasien merasa tidak nyaman dengan situasi tersebut.

Berdasarkan hasil penelitian yang diperoleh dari 30 mahasiswa Jurusan Keperawatan STIKES Tri Mandiri Sakti Bengkulu setelah dilakukan pemijatan menggunakan olive oil terdapat 14 orang mengalami penurunan rasa sakit, dengan rincian 3 orang mengalami perubahan rasa sakit dari kategori sedang ke ringan, 7 orang mengalami perubahan rasa sakit dari kategori parah ke sedang dan 4 orang mengalami penurunan skala rasa sakit tetapi tetap dalam kategori nyeri sedang. Ini menunjukkan bahwa massase menggunakan olive oil cukup efektif dalam mengurangi intensitas rasa sakit pada siswa perempuan yang mengalami dismenore. Kondisi ini disebabkan oleh perasaan pasien yang rileks setelah dipijat.

Sesuai dengan teori menurut Guyton (2010) menyatakan bahwa secara klinis jika pasien rileks maka dapat menyebabkan peningkatan kadar serotonin yang merupakan salah satu neurotransmitter yang diproduksi oleh nucleus rafe magnus dan locus seruleus, juga berfungsi dalam sistem analgesik otak. Serotonin yang menyebabkan neuron lokal dari sumsum tulang belakang untuk mengeluarkan encephaline, karena encephaline diperkirakan menyebabkan hambatan presinaptik dan postinaptik dalam serat nyeri tipe $\mathrm{C}$ sehingga dalam sistem analgesik dapat memblokir sinyal nyeri pada dan $\alpha$ yang merupakan titik masuknya ke dalam sumsum tulang belakang dan memiliki peran dalam serat nyeri tipe $\mathrm{C}$ sehingga sistem analgesik dapat memblokir sinyal nyeri pada $\delta$ dan $\alpha$ yang merupakan titik masuk ke sumsum tulang belakang dan memiliki peran berbagi dalam memodulasi nyeri di sistem saraf pusat.

Selain itu ditemukan 2 orang mengalami peningkatan rasa sakit, yaitu pada 1 mahasiwa yang pada saat terapi responden dalam keadaan tidak enak badan sehingga mempengaruhi hasil terapi yang dilakukan. Selain 1 responden lainnya ketika melakukan terapi 
mengatakan bahwa dia stres karena ada masalah sehingga akan mempengaruhi emosi pasien yang sedang bekerja pada menstruasi yang lancar dan dapat meningkatkan rasa sakit dismenore.

Selain itu setelah terapi pijat menggunakan olive oil ada 14 orang tidak mengalami perubahan rasa sakit. Hasil ini terjadi karena responden mengatakan mereka tidak terbiasa memijat sehingga ketika wawancara dilakukan responden merasa tidak nyaman dan tidak rileks sehingga tidak mempengaruhi skala nyeri dismenore.

Berdasarkan hasil penelitian yang diperoleh dari 30 siswa Jurusan Keperawatan STIKES Tri Mandiri Sakti Bengkulu setelah dilakukan pemijatan menggunakan olive oil terdapat 14 orang mengalami penurunan rasa sakit, dengan rincian 3 orang mengalami perubahan rasa sakit dari kategori sedang hingga ringan, 7 orang mengalami perubahan rasa sakit dari kategori parah ke sedang dan 4 orang mengalami penurunan skala rasa sakit tetapi tetap dalam kategori nyeri sedang. Ini menunjukkan bahwa massase menggunakan olive oil cukup efektif dalam mengurangi intensitas rasa sakit pada siswa perempuan yang mengalami dismenore. Kondisi ini disebabkan oleh perasaan pasien yang rileks setelah dipijat.

Didukung oleh teori menurut Primadiati (2013), pijatan menggunakan minyak zaitun yang dioleskan atau dipijat pada permukaan kulit, maka minyak atsiri akan diserap oleh tubuh, maka itu akan dibawa oleh sistem sirkulasi baik sirkulasi darah dan sirkulasi limfatik melalui proses pencernaan penyerapan kulit oleh pembuluh kapiler, kemudian, kapiler mengirimkannya ke sistem saraf pusat dan oleh otak akan dikirim pesan ke organ yang terganggu atau tidak seimbang.
Minyak atsiri yang diterapkan melalui massase dapat mempengaruhi sistem tubuh dalam beberapa jam, hari atau minggu, tergantung pada kondisi kesehatan seseorang.

Berdasarkan hasil penelitian ditemukan bahwa ada efek massase menggunakan olive oil pada nyeri dismenore pada mahasiwa Jurusan Keperawatan STIKES Tri Mandiri Sakti Bengkulu. Diharapkan mahasiswa dapat melakukan pijat punggung selama dismenore untuk mengurangi dan mengobati nyeri dismenore karena dalam penelitian ini terbukti bahwa pijat dapat mengurangi nyeri dismenore sehingga penggunaan terapi pijat sebagai langkah utama dalam menangani nyeri dismenore. penggunaan penghilang nyeri haid dipasaran yang tentu mengandung bahan kimia dan dapat menimbulkan efek samping di masa depan karena sifat kimia tersebut akan lebih atau kurang mengalami residu dalam tubuh.

Selain itu, dalam penelitian ini masih ada responden yang tidak mengalami perubahan rasa sakit setelah dipijat menggunakan olive oil sebanyak 14 orang. Ini karena responden tidak terbiasa melakukan pijat punggung, sehingga keadaan rileks tidak dapat dicapai ketika dilakukan dengan menggunakan olive oil, sehingga terapi tidak mempengaruhi skala rasa sakit baik sebelum atau setelah pijat menggunakan olive oil. Kemudian ada kebutuhan untuk alternatif relaksasi lain yang perlu diterapkan untuk membantu mengurangi rasa sakit dismenore yang tidak bersentuhan dengan responden, seperti terapi relaksasi napas dalam, terapi kompres hangat dan guided imagery therapy 


\section{Simpulan}

Hasil penelitian menunjukkan efek massase menggunakan olive oil pada nyeri dismenore pada mahasiswa keperawatan STIKES Tri Mandiri Sakti Bengkulu, dan ada perbedaan antara tingkat nyeri sebelum terapi massase dan setelah terapi massase. Hasil penelitian dapat menjadi bahan utama pembelajaran sistem reproduksi. Selanjutnya, perawat dapat menggunakan hasil penelitian ini sebagai bahan rujukan dalam memberikan informasi dan edukasi kesehatan kepada

\section{Daftar Pustaka}

Agustina, T, W. 2016. The Influence of Jasmine Effleurage Aromatherapy on the Level of

Dysmenorrhea in Nursing Students in Semester IV University of 'Aisyiyah Yogyakarta: Nursing Studies Program at the Faculty of Health of the University of Aisyiyah Yogyakarta. Page 1-4 Accessed on November 5, 2018, from file: /// C: /Users/acer/Documents/NASKAH\%20PU BLICATION\%20201210201072.pdf.

French, L. 2014. Dysmenorrhea.American Academy of Family Physicians. Journal: American

Family physician vol 89 (5): hal 1-6 www.aafp.arg/afp.

Gloria, M. B., 2013. Nursing Interventions Classification NIC.Sixth edition.Level 3, intervention promotion 1130. Elsevier: United Stated of America.

Guyton \& Hall. 2010. Textbook of Medical Physiology. 9. Jakarta Edition: EGC Medical Book Publisher

Harel, B. 2011. Concept and Management of Pain. Jakarta: EGC

Hidayat, A.A. 2011. Handbook of Practices for Basic Human Needs. Jakarta: Salemba Medika

Kumalasari, I. 2013. Reproductive Health for Midwifery and Nursing Students. Jakarta: Salemba Medika.

Nuzul Eka Yoganita et al (2019), The Benefits of Nape Massage With Olive Oil To Reduce Headache on Hypertension Patients. Joernal Profesi (Profesional pasien yang mengalami dismenore untuk dipijat menggunakan olive oil sebelum menggunakan obat penghilang rasa nyeri menstruasi di pasaran, dengan melakukan pemijatan menggunakan olive oil akan meningkatkan kenyamanan bagi pasien sehingga dapat mengurangi nyeri dismenore.

Islam) Media Publikasi Penelitian. Volume 16; No. 2. Hal.3439.ejournal.stikespku.ac.id

Primadiati, R. 2013. Aromatherapy - Natural Treatments for Health and Beauty. Jakarta:

Gramedia Main Library

Proverawati.2012. Menarche Menstruation First Fully Meaning. NoahMedika: Yogyakarta.

Reeder,dkk. 2011.Keperawatan Maternitas :Kesehatan Wanita, Bayi dan Keluarga. 18

edisi.Jakarta : EGC

Smeltzer, S.,Bare, B.,Hinkle, J.L.,\& Cheever, K.H.(2010).Brunner \& Suddenth'textbook of medical-surgical nursing (12 ed.).Philadelphia:Lippincott Williams \& Wilkins.

Smeltzer, S.C., \& Bare B.G. 2013, Surgical Medical Teaching Book. Jakarta: EGC

Speroff, L. Fritzz, M. A. 2013. Clinical Gynecologic Endocrinology and Infertility, 7thed.

Lippincot William and Wilkins: Philadelphia.

Sulistyowati, 2015. Mass Effect of Lavender Aromatherapy on Cancer Pain in Rsud Ulin Banjarmasin: Journal of the Graduate Program of the Faculty of Nursing. University of Indonesia Accessed on 5 November 2018 from http://lib.ui.ac.id/file?file=digital/201610/20438027-Reny\%20Sulistyowati.pdf 
Wisdom. N. 2012. The influence of the administration of aroma therapy oil massage substance

on the decrease in the intensity of dysmenorrhea pain in young women at SMK Negeri 2 Malang Department of Nursing. SI Midwifery Study Program, Faculty of

Medicine, University of Brawijya Journal of Issues in Midwifery vol 2 (2): pp 34-45 Accessed on 25 November 2018, from http://joim.ub.ac.id/index.php/joim/article /

view / 60. 